\title{
Fashion Design Bases on Computer Three-Dimensional Virtual Reality Environment
}

\author{
Xinyun Zhou*
}

Gannan Normal University, GanZhou, JiangXi, China

\begin{abstract}
In order to meet the application requirements of the textile and garment industry, the three-dimensional garment simulation usually requires different features of the human body to show the effect of wearing such clothing as well as three-dimensional fitted and so on. This paper takes into account the practical application of a new method for parameterized mannequin modeling. Determining the characteristic parameters based on anthropometric theory, templates, and the results of the model are represented as space polygon mesh, i.e. the underlying geometry processing technology based on computer graphics axial deformation, while the radial deformation flexibility to increase the weight curve adjustment is introduced. This method is simple, intuitive, and modeling input speed advantage, that can effectively meet the needs of the three-dimensional garment simulation environment for personalized mannequin.
\end{abstract}

Keywords: Computer, fashion design, three-dimensional, virtual reality.

\section{INTRODUCTION}

The virtual reality of "immersive" refers to the user fully immersed in the computer generated 3D virtual environment, and produce immersive feel. Virtual reality "interactive" refers to the user to use visual, hearing, touch, smell and taste sensory function and dialogue, head movements, such as eye movement, walk, turn, pick and place the natural human entities in the virtual environment to interact with the operation [1]. As a result, virtual reality system will fundamentally change the way people interacts with the computer system, as shown in Fig. (1).

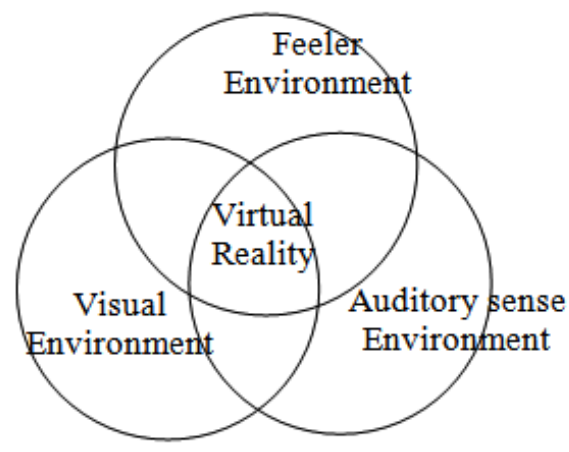

Fig. (1). The structure of virtual environment.

At present, fashion virtual display technology is largely based on geometrical or physical method. For the former, lower calculation cost, better real-time performance, but need more human intervention, and as a result of not considering the quality of the fabric, elastic coefficient, physical factors, such as the external environment change completely

*Address correspondence to the author at the Gannan Normal University, GanZhou, JiangXi, China; Tel: + 86-130-7419-3880;

E-mail: luoml@vip.qq.com according to the algorithm designers experience, knowledge of mathematics, geometry modeling etc., so it is difficult to generate lifelike clothing outfit effect. For the latter, to some extent, enhance the sense of reality [2], but at the same time increase the computational complexity, lower the garment simulation and real time. Even in high performance workstations, calculating a frame image mostly takes a few seconds and even a few days time, this is obviously unable to meet the needs of real-time rendering.

\section{THREE-DIMENSIONAL HUMAN BODY MODEL PARAMETERIZATION}

\subsection{Characteristic Parameters Defined}

Human body modeling is the first of this paper to solve the problem of parameter selection. The reference to relevant principles and methods of the anthropometry, determine the parameters for the eight basic human characteristics: high height, hip, long arms, neck circumference, chest circumference, chest circumference, waist, and hip circumference. These parameters have stronger relative independence, and generally easy to obtain [3].

\subsection{Template Parameter Measurement}

The length of the information of the period of the template to the human body is based on the measurement. In adult female model, for example, 1 set of measuring plane can be divided into buttock, left arm, right hand, left leg, left leg, right, right leg, right leg and left foot 15 pieces. Each section consists of the associated datum plane (Fig. 2) and a number of planes, choosing these auxiliary planes, is the displacement Poffset, length of Pbase and Poffset is both planes' distance of local origin of coordinates.

By measuring the length of the paragraphs calculation template forms characteristic parameters of the following (assuming the body left and right sides are symmetrical): 


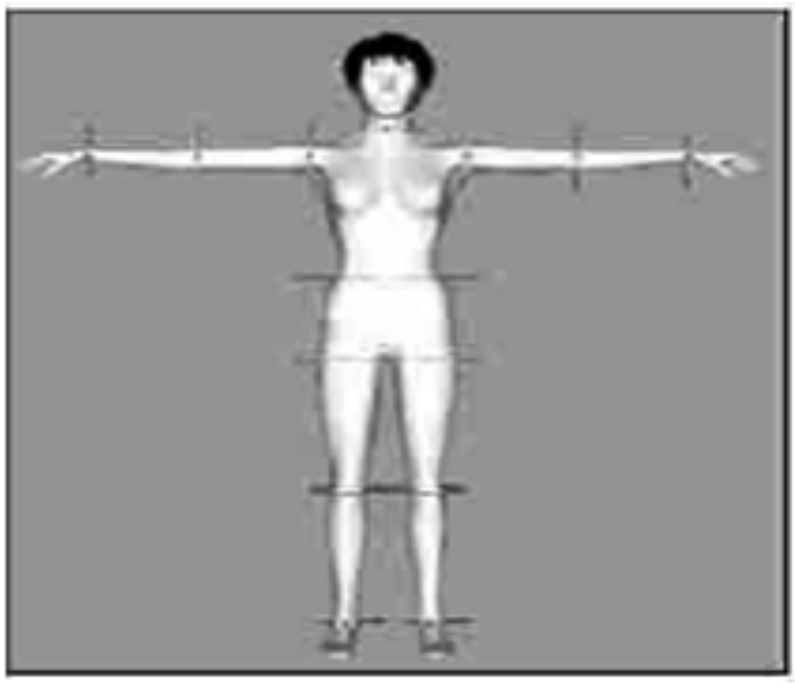

Fig. (2). The schematic diagram of anthropometric parameters.

With no auxiliary plane, section processing method is as follows: a computing grid vertices in local coordinates Pbase extremum ymax along the y direction, and then introduces according to the section on Pbase plus or minus half space plane Poffset displacement. If it is positive, Poffset from $(0$, ymax, 0) Pbase method is to determine the direction. If negative, Poffset origin in $(0,-y m a x, 0)$, the normal vector and Pbase have corresponding value instead [4].

Surrounded degree measurement associated with the cross section contour of template geometry, is shown in Fig. (2) hip circumference measurement. For measuring plane P, translation and rotation operations are applied to place it in specific areas of the template, calculating intersecting contour xoz plane and the local coordinate system of two dimensional convex hull, and then to the convex hull polygon perimeter as a measure of actual value [5].

\section{MODELING SYSTEM IMPLEMENTATION}

Human body modeling system contains 2 class control body, respectively the length of the template and the degree of deformation, both with shaft deformation technology, when only the control method is different.

\subsection{Deformation Control of Body}

Deformation control is performed using cubic spline interpolation method. The definition of cubic spline interpolation is as follows. Equipped with a subdivision $\Delta: \mathrm{a}=\mathrm{t}_{0}<\mathrm{t}_{1}<\cdots<\mathrm{t}_{\mathrm{n}}=\mathrm{b}$, If the function $\mathrm{S}(\mathrm{t})$ meets the following conditions (W.J. Jie, F Jin. 2000; N. Hui, X.N. Luo, 2012):

(a) $\mathrm{S}(\mathrm{t}) \epsilon \mathrm{C}^{2}[\mathrm{a}, \mathrm{b}]$

(b) $\mathrm{S}(\mathrm{t})$ in every village $\left[\mathrm{t}_{\mathrm{i}}, \mathrm{t}_{\mathrm{i}+1}\right]$ is the number 3 or less polynomial:

Delta $\Delta$ is called $\mathrm{S}(\mathrm{t})$ at subdivision of a three spline function. For a given 3D curve, function table $\left(\mathrm{t}_{\mathrm{i}}, \mathrm{p}\left(\mathrm{t}_{\mathrm{i}}\right)\right),(\mathrm{i}=0,1,2 \cdots \mathrm{n})$, if three times then there is a function type of difference conditions, if (1) of the cubic spline function, $\mathrm{S}(\mathrm{t})$ also meets interpolation conditions:

$\mathrm{S}(\mathrm{t})=\mathrm{p}\left(\mathrm{t}_{\mathrm{i}}\right),(\mathrm{i}=0,1,2 \cdots \mathrm{n})$

Is called the $\mathrm{S}(\mathrm{t})$ delta $\mathrm{p}\left(\mathrm{t}_{\mathrm{i}}\right)$ on the subdivision of a cubic spline interpolation function.

The calculation of cubic spline interpolation function $\mathrm{S}(\mathrm{t})$, due to requirements $\mathrm{S}(\mathrm{t})$ is 3 times polynomial on $\left[\mathrm{t}_{\mathrm{j}}, \mathrm{t}_{\mathrm{j}+1}\right]$, is

$\mathrm{S}(\mathrm{t})=\mathrm{S}_{\mathrm{j}}(\mathrm{t})=\mathrm{a}_{\mathrm{j}}+\mathrm{b}_{\mathrm{j}} * \mathrm{t}+\mathrm{c}_{\mathrm{j}} * \mathrm{t}^{2}+\mathrm{d}_{\mathrm{j}} * \mathrm{t}^{3}$

Of which, a total of $4 \mathrm{n}$ undetermined coefficients $\left\{a_{j}\right\},\left\{b_{j}\right\},\left\{c_{j}\right\},\left\{d_{j}\right\}$, to determine $\mathrm{S}(\mathrm{t})$ and to determine $4 \mathrm{n}$ undetermined coefficients.

And

$\mathrm{S}(\mathrm{t})=\mathrm{p}\left(\mathrm{t}_{\mathrm{i}}\right),(\mathrm{i}=0,1,2 \cdots \mathrm{n})$

A total of $4 \mathrm{n}-2$ conditions, and the given boundary conditions: $\quad \mathrm{S}^{\prime}\left(\mathrm{t}_{0}\right)=\mathrm{p}_{0}^{\prime}, \mathrm{S}^{\prime}\left(\mathrm{t}_{\mathrm{n}}\right)=\mathrm{p}_{\mathrm{n}}^{\prime}$. Now $\mathrm{S}^{\prime}\left(\mathrm{t}_{\mathrm{j}}\right)=\mathrm{m}_{\mathrm{j}} \mathrm{S}(\mathrm{t})$ actually meets the conditions,

remember

$\left\{\begin{array}{c}S\left(t_{j}\right)=p\left(t_{j}\right) \\ S^{\prime}\left(t_{j}\right)=m_{j},(j=0,1, \nwarrow n)\end{array}\right.$

$\mathrm{S}(\mathrm{t})=\mathrm{S}_{\mathrm{j}}(\mathrm{t})=\mathrm{p}_{\mathrm{j}}+\mathrm{c}_{\mathrm{j}, 1} *\left(\mathrm{t}-\mathrm{t}_{\mathrm{j}}\right)+\mathrm{c}_{\mathrm{j}, 2} *\left(\mathrm{t}-\mathrm{t}_{\mathrm{j}}\right)^{2}+\mathrm{c}_{\mathrm{j}, 3} *\left(\mathrm{t}-\mathrm{t}_{\mathrm{j}}\right)^{3}$

(5)

$$
\left\{\begin{array}{c}
c_{j, 1}=m_{j} \\
c_{j, 2}=\left(\frac{3\left(p_{j+1}-p_{j}\right)}{h_{j}}-2 m_{j}-m_{j+1}\right) \frac{1}{h_{j}} \\
c_{j, 3}=\left(m_{j+1}+m_{j}-\frac{2\left(p_{j+1}-p_{j}\right)}{h_{j}}\right) \frac{1}{h_{j}}
\end{array}\right.
$$

If $\left\{\mathrm{m}_{\mathrm{j}}\right\}_{\mathrm{j}=0}^{\mathrm{n}}$ satisfies the system of linear equations

$c_{j, 2}=c_{j-1,2}+3 * c_{j-1,2} * h_{j-1},(j=1,2, \nwarrow n-1)$

Then get $\left\{m_{j}\right\}$ that meets the system of linear equations by $n-1$ :

$$
\begin{gathered}
\nwarrow_{j} m_{j-1}+2 m_{j}+u_{j} m_{j+1}=g_{j} \\
\searrow_{j}=\frac{h_{j}}{h_{j}+h_{j-1}, u_{j}=1-\searrow_{j}} \\
g_{j}=3\left(u_{j} \frac{p_{j+1}-p_{j}}{h_{j}}+\searrow_{j} \frac{p_{j}-p_{j-1}}{h_{j-1}}\right. \\
S_{j}=t_{j+1}-t_{j},\left(j=1,2, \searrow_{n}-1\right)
\end{gathered}
$$

Type is about, $\mathrm{m}_{0}, \mathrm{~m}_{1}, \mathrm{~m}_{\mathrm{m}}, \mathrm{n}-1$ equation, boundary conditions:

$\mathrm{S}\left(\mathrm{t}_{0}\right)=\mathrm{p}_{0}=\mathrm{m}_{0}, \mathrm{~S}\left(\mathrm{t}_{\mathrm{n}}\right)=\mathrm{p}_{\mathrm{n}}=\mathrm{m}_{\mathrm{n}}$ 
Then, $\left\{m_{j}\right\},(\mathrm{i}=0,1,2, \ldots \mathrm{n})$ To work out, $c_{j, 1}, c_{j, 2}, c_{j, 3}$ In the above equations, the cubic spline interpolation function $\mathrm{S}(\mathrm{t})$ is acquired.

\subsection{The Generation of Personalized Human Body Model}

In the model of human body characteristic data and customer data similarity matching between human characteristics, matching degree is the highest considered and the most consistent with customers shape characteristics of the fitting [6].

In this paper, based on the similarity case retrieval algorithm, definition of similarity is the similarity degree (SD), between two objects. Such as similarity of the object $X, y$ expressed is with $\operatorname{sum}(\mathrm{x}, \mathrm{y})$, then $\operatorname{sum}(\mathrm{x}, \mathrm{y}) \in[0,1]$, satisfies the following conditions:

a. $\operatorname{Symmetry}, \operatorname{sum}(\mathrm{x}, \mathrm{y})=\sin (\mathrm{y}, \mathrm{x})$;

b. Reflexive, $\operatorname{sum}(\mathrm{x}, \mathrm{y})=1$;

c. negative, $\operatorname{sum}(\mathrm{x}, \mathrm{y}) \geq 0$;

Similarity between two objects is the difference in the value of object size, namely the object. The concept of distance between two objects of the similarity function of the distance is achieved by limiting its range between 0 and 1 . That is when similarity is zero, there are no similar characteristics; when similarity is equal to 1 , and it means they have completely similar characteristics [7]. Usually an object has three types of values: value, scope and fuzzy value. The three types of values form six different similarity calculation parameters, whose description is as follows:

1) Two similarity numericals calculating and determining the values $a, b$ with the similarity calculation formula, are defined as follows:

$\operatorname{sim}(x, y)=-\frac{|x-y|}{\nwarrow \searrow}$

For type, $\mathrm{x}$, y value of lower limit and upper limit respectively, we can determine the similarity calculation formula of numerical, extended to the similarity calculation between interval and fuzzy value.

2) The similarity calculation of the numerical between scope of numerical $\left[b_{1}, b_{2}\right] a$, and interval is defined as similarity calculation formula.

Formula (11) is generated from formula (10) evolution, which represents a definite value $\left[b_{1}, b_{2}\right]$ a and interval on a certain similarity level of the average value $b \quad b \in\left[b_{1}, b_{2}\right]$. This situation is used to compute similarity between two objects to determine the situation; however it only tells if an object belongs to another object contained in the interval [8].

3) Values and fuzzy member similarity calculation between $\mathrm{x}(\mathrm{x})$ fuzzy values, formulas are defined as follows:

4) Formula for the similarity calculation between interval $\left[a_{1}, a_{2}\right],\left[b_{1}, b_{2}\right]$ is defined as follows:

$\operatorname{sim}\left(\left[a_{1}, a_{2}\right],\left[b_{1}, b_{2}\right]\right)=\frac{\int_{a_{1}}^{a_{2}} \int_{b_{1}}^{b_{2}} \operatorname{sim} \operatorname{sim}(x, y) d y d x}{\left(a_{2}-a_{1}\right)\left(b_{2}-b_{1}\right)}$
5) The fuzzy value interval between [a1, a2] and fuzzy value $\mathrm{X}(\mathrm{X})$ of similarity calculation formula are defined as follows:

6) The fuzzy value is calculated. And formula for similarity calculation between the two fuzzy values $\mathrm{Xa}, \mathrm{Xb}$, is defined as follows:

Among them $a, b$ are the value of fuzzy values of lower limit and upper limit.

Two single object similarity calculation is done. When two objects are made up of multiple bodies, their similarity can be calculated with composite similarity calculation formula defined as follows [9]

$\mathrm{S}(\mathrm{X}, \mathrm{Y})=\sum_{i=1}^{n}\left[\nwarrow_{\mathrm{i}}, \operatorname{sim}\left(\mathrm{x}_{\mathrm{i}}, \mathrm{y}_{\mathrm{i}}\right)\right]$

The formula consists of two separate package attributes of X, Y; the similarity calculation formula of type $\mathrm{Y}$ is said to affect of X.Y similarity degree through a property, namely the weight.

\section{THE APPLICATION OF 3-D GARMENT SIMULA- TION INSTANCE}

In this chapter using VRML format, apparel network model is established, and the detailed modeling process is given. And then, on the basis of the network model, the network interaction technology based on VRML is studied. The interaction design architecture is shown in Fig. (3).

3D garment simulation environment models the human body as the carrier of clothing from preliminary design to the entire process, which is an important factor affecting the quality of the simulation. This paper proposes a fast parametric modeling method, and implements the corresponding human body modeling system, listed below are the results of the model application instance [10].

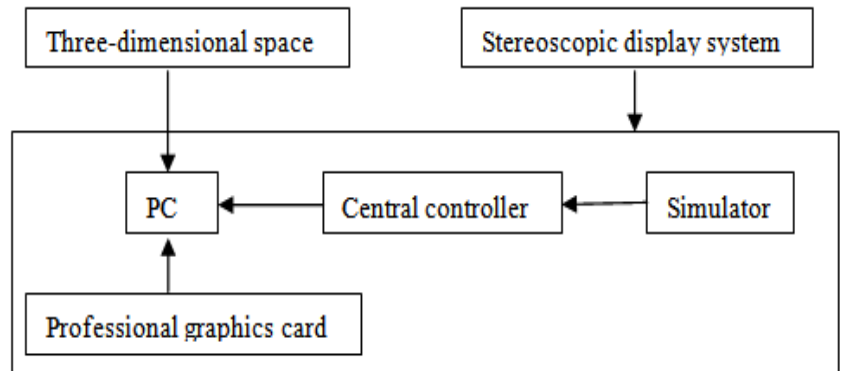

Fig. (3). Three-dimensional virtual operating model.

Fig. (4) shows the three-dimensional human body model participating in the process of virtual stitching pieces. The pieces are placed around the human body model for configuration, and then using physical simulation, converted the two-dimensional pieces to $3 \mathrm{D}$ garment. In addition to the graphical objects, the human body model is also used for real-time collision detection and response calculation.

Try with the same piece of clothing on posture characteristics for finding different wearing effect which is significant. In addition to the human body model, one can choose virtual try on different sizes of the same style; its broader 
application will involve clothing ordering based on the Internet, sales, and display, etc.

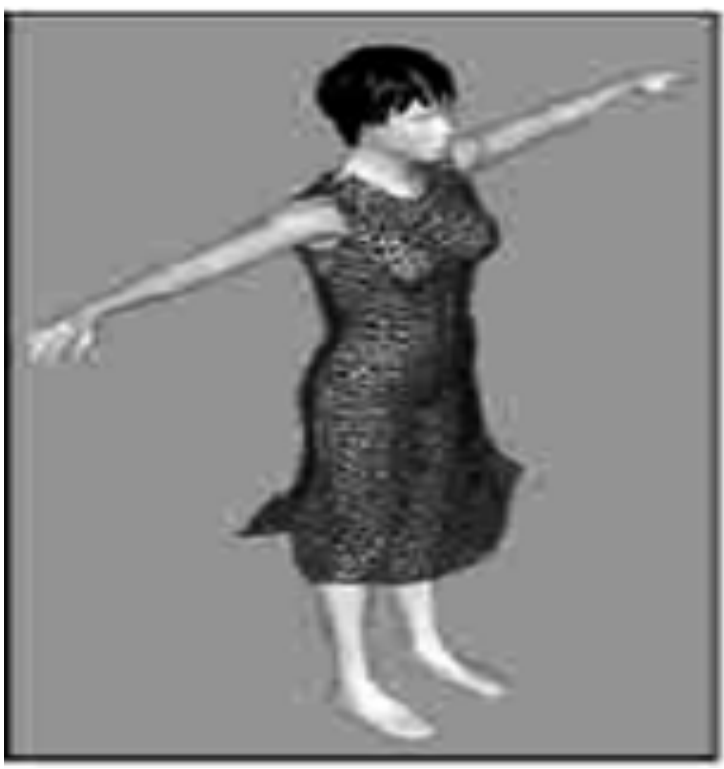

Fig. (4). Seaming $3 \mathrm{D}$ cloth patches for a specific mannequin.

\section{CONCLUSION}

In order to overcome the problems of $3 \mathrm{D}$ garment simulation of the human body modeling, this paper proposes a new method. Through the geometry of the template the method is modified to implement the rapid generation of clothing for specific human body model, which involves key techniques such as defining the measurement plane parameter information to extract human body template form; introducing the parameters of axial to increase the shaft deformation algorithm, the length and the degree of deformation control body structure and deformation control etc. From the viewpoint of system application, the method provides an intuitive input interface include only a few visual characteristic parameters of the human body, and the end user does not need to make any geometry processing modeling at the level of interaction, and it also guarantees a simple and efficient modeling work.

\section{CONFLICT OF INTEREST}

The authors confirm that this article content has no conflict of interest.

\section{ACKNOWLEDGEMENTS}

Declared none.

\section{REFERENCES}

[1] X.Y. Ma, and X.L. Feng, "Advances in three-dimensional garment simulation technology," Textile Journal, vol. 25, no. 4, pp. 122 124, 2004.

[2] N.Liu, and X.N. Luo, "Establishing virtual dressing and collision detection in the fabric model processing," Computer Applications, vol. 22 , no. 5 , pp. 34-37, 2012

[3] G.Z. Zhu, and M.J. Li, "Three-dimensional clothing CAD garment research technology status," Knitting Industry, no. 4, pp. 55- 57, 2005

[4] W.J. Jie, and F Jin, "Clothing mannequin's parametric featurebased modeling method," Central China University of Technology, vol. 28 , no. 1 , pp. $27-32,2000$.

[5] N. Hui, and X.N. Luo, "Three-dimensional virtual research suture technique clothing," Computer Aided Design and Computer Graphics, vol. 14, no. 11, pp. 1010-1013, 2012.

[6] M.H. Tang, J. He, Zh.Y. Zhang, et al., "Suture technique based on virtual garment draping knowledge," Textile Journal, vol. 25, no. 2 , pp. 95-97, 2010.

[7] Y. Li, M. Hu, and X.L. Fu, "Study the three-dimensional modeling of the human body," Textile Technology, vol. 23, no. 5, pp. 416$418,2013$.

[8] Y.Q. Zhong, and S. Y. Wang, "Fabric and garment simulation technology progress," Textile Journal, vol. 23, no. 6, pp. 502-504, 2012.

[9] Q.F. Zhuang, F.Wu, and Y.L. Ding, "Parametric study of threedimensional garment CAD mannequin," Computer Aided Design and Computer Graphics, vol. 16, no. 7, pp. 918-920, 2011.

[10] J. Xu, "Virtual three-dimensional garment technology research and development," Shanghai Textile Science and Technology, vol. 30, no. 3 , pp. $56-58,2012$.

Received: May 26, 2015

(C) Xinyun Zhou; Licensee Bentham Open.

This is an open access article licensed under the terms of the (https://creativecommons.org/licenses/by/4.0/legalcode), which permits unrestricted, noncommercial use, distribution and reproduction in any medium, provided the work is properly cited. 